- or direct comparisons between stapler transection and the various other manual procedures on or around the lower oesophagus. The evidence accumulating from uncontrolled reports of stapling/transection are at present sufficiently good, however, to suggest that this technique may now be the first choice when a direct surgical attack on the varices is indicated. If the surgeon either has no access to a stapler or no experience with the technique, then he is left with the choice between transection and reanastomosis or multiple ligation of the varices under direct vision-not always an easy procedure.

Finally, are shunts obsolete? Not yet, but if they are to continue to have a place in the overall management of cirrhosis with portal hypertension-then probably they will be selective rather than total, performed only on patients with reasonably good liver function (not as emergency procedures) and undertaken in selected centres by teams with special skills in both the operations and, as important, the management of the problems of liver failure.

Professor of Surgery,

IAIN E GILLESPIE

Royal Infirmary,

Manchester M13 9WL

1 Sarles HE Jr, Sanowski RA, Talbert G. Course and complications of endoscopic variceal sclerotherapy: a prospective study of 50 patients. Am f Gastroenterol 1985;80:595-9.

Terblanche J. A review of injection sclerotherapy-the Cape Town experience. fpn 7 Sur 1985;15:103-11.

3 Soderlund C, Ihre T. Endoscopic sclerotherapy v conservative management of bleeding oesophageal varices. A 5-year prospective controlled trial of emergency and long-term treatment. Acta Chir Scand 1985;151:449-56.

4 Westaby $D$ Williams $R$. Injection sclerotherapy for the long-term management of variceal bleeding. World I Surg 1984;8:667-72.

Giordani M, Ravo B, Sacchi M, Smith N, Ger R. Treatment of bleeding oesophageal varices by portoazygous disconnection and oesophageal transection with the button of Boerema and EEA portoazygous disconnection and oesophageal transection

\section{Staying cool with a hot test: gastroenterologists and ${ }^{75}$ SeHCAT}

Clinical tests of small intestinal function are few and crude. In part this is due to overlap in the absorptive functions of the jejunum and ileum; but the ileum has two functions unique to itself-active absorption of vitamin $\mathrm{B}_{12}$ and active absorption of bile salts. Furthermore, the active transport of bile salts is limited to the terminal ileum ${ }^{1}$; all we need to assess the function of the terminal ileum is a good test of bile salt absorption (on the reasonable assumption that most of this absorption occurs by active transport).

In the past, tests of bile salt absorption were too complicated and tedious for routine clinical use-but then ${ }^{75} \mathrm{SeHCAT}$ became available in January 1985. This selenium-75 labelled artificial bile salt, a homologue of taurocholate, has transformed matters. Now with nothing more complicated than a gammacamera any nuclear medicine department can measure how efficiently the circulating pool of bile salts is retrieved from the ileum and returned to the biliary tract.

This test seems like the answer to the gastroenterologist's prayer. After all, one of the biggest challenges in gastroenterological practice is Crohn's disease, which affects the terminal ileum more often than any other part of the gut. Yet at a recent conference on new radioactive tests in gastroenterology -at which most attention was given to the ${ }^{75} \mathrm{SeHCAT}$ test-the audience stayed calm, even cool, during discussion of this test. ${ }^{2}$ Later I sent a postal questionnaire to 43 randomly chosen British gastroenterologists about their usew of and views on the test and had replies from 38 of them $(88 \%)$. Only six had the test available in their hospital. Onlyo five of the other 32 admitted to being unhappy without it.

Why are gastroenterologists showing so little interest? Firstly, in Crohn's disease the function of the terminal ileum? is usually undisturbed until structural changes are obvious on a good barium study. Secondly, simple tests for inflamma tion like the plasma concentration of $\mathrm{C}$ reactive protein and? seromucoids and the platelet count are quite sensitive, if non $\overrightarrow{\vec{F}}$ specific, pointers to the disease. Thirdly, new scanning tests especially the indium-111 leucocyte scan, are coming intouse $^{2-4}$ (they are used by 12 of the 38 gastroenterologists in my survey).

If ${ }^{75} \mathrm{SeHCAT}$ has a future it is not with Crohn's disease but with an even more elusive condition, idiopathic bile salt ${ }^{\text {s }}$ malabsorption. Unabsorbed bile salts cause watery diarrhoea. and some gastroenterologists claim that they are responsible $\vec{\omega}$ for between one quarter and one half of their cases of obscureo diarrhoea-patients who would otherwise be labelled as 3 having the irritable bowel syndrome. ${ }^{5} 6$ Possibly thesei patients malabsorb bile salts because chyle moves too fastiv through the terminal ileum, but nobody really knows whyo the ileum fails in its duty of reabsorbing bile salts- struc- $\perp$ turally it appears normal. ${ }^{5}$ This disorder is important because $\overrightarrow{\vec{f}}$ specific and effective treatment is available in the form of cholestyramine and other bile salt binding resins; and to응 diagnose it we now have a simple, safe, and specific test-the $v$ ${ }^{75}$ SeHCAT test.

The case for ${ }^{75} \mathrm{SeHCAT}$ seems clear cut-the gastroenterologist without it cannot diagnose a disabling condition. $\vec{\bullet}$ Yet this is not really so. The diagnosis may be made in another way, which is simpler and cheaper: try the treatmento and see if it works. By definition diarrhoea induced by bile acid is cured by cholestyramine. The pragmatic doctor sees nothing to gain from ${ }^{75} \mathrm{SeHCAT}$ except intellectual satisfaction -an expensive luxury, perhaps, at $£ 50$ a dose plus labour@ costs.

Might it be argued that since cholestyramine is a tedious if 3 not unpleasant powder to take doctor and patient alike will not be motivated to stick to the treatment unless they have the result of a test to back their subjective impressions? That does not seem to me a convincing argument. If symptoms are bad and a treatment works the patient takes the treatment.

Furthermore, antidiarrhoeal agents which are easier to take may be just as effective, even if they are less specific. Resistance to loperamide is not a reported feature of idiopathic bile acid diarrhoea. Loperamide slows down small bowel ${ }^{\supset}$ transit and would be expected to improve bile acid absorption when impaired by rapid ileal transit.?

${ }^{75}$ SeHCAT is an elegant and powerful research tool, allowing the enterohepatic circulation of bile salts to be $N$ studied more easily and in greater detail than ever before.. With current financial restraints, however, the case fore including it in the techniques of evey nuclear medicine? department has yet to be proved.

Reader in Medicine,

University of Bristol,

Bristol Royal Infirmary,

Bristol BS2 8HW

K W HEATONT

Weiner physiology. Sect 6. Alimentary canal. Vol 3. Intestinal absorption. Washington: American

2 Heaton KW. Now you see it, now you don't! $7 R$ Soc Med (in press).

3 Saverymuttu SH, Peters AM, Lavender JP, Hodgson HJ, Chadwick VS. ${ }^{111}$ Indium autologous leucocytes in inflammatory bowel disease. Gut 1983;24:293-9. 
4 Dawson DJ, Khan AN, Miller V, Ratcliffe JF, Shreeve DR. Detection of inflammatory bowe disease in adults and children: evaluation of a new isotopic technique. Br Med $\mathcal{J}$ 1985;291 $227-30$

5 Thaysen EH, Pedersen L. Idiopathic bile acid catharisis. Gut 1976;17:965-70.

6 Merrick MV, Eastwood MA, Ford MJ. Is bile acid malabsorption underdiagnosed? An evaluation of accuracy of diagnosis by measurement of SeHCAT retention. Br Med f 1985;290:665-8.

Cann PA, Read NW, Holdsworth CD, Barends D. Role of loperamide and placebo in management of irritable bowel syndrome (IBS). Dig Dis $S$ ci 1984;29:239-47.

\section{Clinical competence and curiosity}

Medicine is both science and art; small wonder, then, that clinical competence-a blend of knowledge, intellect, attitudes, wisdom, and practical skills-is not precisely measurable. Critics are calling for attempts to refine the testing of clinical competence; but would greater precision be useful? Would the microscope be better focused instead on another area of the large slide of medical education?

In the eyes of examiners, candidates, and the General Medical Council the prime purpose of the medical qualifying examination is to certify sufficient knowledge, sense, and practical skill for a safe start to a long apprenticeship. The examination is not and does not pretend to be an assay of all aspects of medical education nor a complete test of medical competence, several facets of which will develop only later during supervised responsibility.

The emphasis in both the qualifying and later specialist clinical examinations is on a sensible approach and technical competence-more the science than the art. That is not to say that examiners overlook sympathetic consideration of the patient as a person, even if most would hestitate to put a numerical value to their judgment of this aspect. Sympathy, human insight, and the art of communication are all tested in a pragmatic way as part of the flesh on the skeleton of clinical wisdom and technical competence. Even the marks awarded for clinical ability are softer than hard digits might imply: performance depends both on the particular case given and on the individual opinions of examiners. ${ }^{1}$ So should we be trying to standardise both examiners and patients? Should we be attempting to eliminate the rough edges of real clinical settings from the circumstances of assessment - or is that not the point at all?

If we had a more precise rank order of candidates in the qualifying examination would we make any use of it? Could we be convinced that the ranking had any more meaning than one shake of a kaleidoscope that will be shaken many more times before the doctor's education is complete? Would attempts at greater precision in ascertaining the outcome of an educational process yield information valuable enough to justify loading students with a further burden of assessment? Might it not be sensible and sufficient to settle for the current written, oral, and practical examinations_-which most candidates pass because they are competent for their years and able to continue to learn? A few who perform outstandingly well on the day get honours; a few lazy, uninterested, distracted, or simply unlucky fail.

The qualifying examination is only one (important) hurdle in a long continued process of education and training. The best academic acrobats by no means necessarily turn out to be the most effective members of the professional circus, which is not surprising because enthusiasms wax and wane, individuals mature at different rates, the wide variety of jobs in medicine demands a panopoly of different skills and catches different imaginations, and there are many and varied colleagues and consumers to satisfy.

None the less, it is an interesting task and, indeed, the academic fodder of educationalists to dissect out the components of competence and to improve assessment. Some, such as Neufeld and his colleagues at McMaster, ${ }^{2}$ have approached the issue with critical good sense. They ask of any proposed test of clinical competence whether it tests what it claims to test, measures performance consistently, is applicable, is acceptable, and whether it achieves a useful educational purpose. Examinations are not only milestones of achievement but also useful means of instruction and correction, instruments of emphasis, and avenues of insight into the success or failure of education. Clearly assessments should be as informative and reliable as possible, but at the same time their pragmatic purpose may be achieved without fine (and probably illusory) precision.

Neufeld has aptly described clinical competence as a "battered child": "child" because a relatively new topic of interest; "battered" because maltreated by some researchers. ${ }^{3}$ Some have lacked understanding of the nature of clinical practice and responsibility; others have failed to appreciate the gap between their untreated theories and obscure jargon and the down to earth views of those whom they seek to persuade. Educationalists who, for example, write that they "wish to challenge the view that competence in medicine is completely specified by the acquisition of a body of facts" are tilting at windmills and cannot expect the confidence of either those who teach or those who learn. ${ }^{4}$ Nor can clinical teachers take seriously those who write "In considering the potentially large number of exposures required to adequately interpret any finding and the large number of physical signs available, it is a frightening possibility that the amount of exposure of a typical undergraduate may be woefully inadequate."

It is not just "possible" but certain that clinical skills are incomplete on qualification; incompleteness does not prevent newly qualified students rapidly turning into competent house officers. Certainly every attempt should be made to ensure that clinical experience before qualification is as extensive as possible. The remedy is not "research... to further explore actual exposure in the undergraduate curriculum" but action to ensure that teaching and experience proceed hand in hand and that students are personally accountable and, as far as is possible, responsible for their patients.

Where gaps exist in knowledge untested theories all too easily creep in. The message of Hans Anderson's story of The Emperor's New Clothes is evergreen: we need to see through the eyes of the small boy who, being unable to see gold or silver thread, concluded not that he alone was unable to see the fine cloth but that it was not there. To use another metaphor, we should view education theory with an open mind but not "so open that our brains fall out."

Academic study of clinical skills and their assessment ought to be worth while, but whether they are of practical value remains to be seen. A more important question is how high should such a study rank in the list of priorities for the academic study of the process of medical education? Surely a much more pressing issue is why so many medical students the world over lose their curiosity and enthusiasm as they pass through their course. Nearly 20 years ago a student wrote: "In every clinical student a spark of enthusiasm for medicine must grow, else he would never have taken to the profession, but somewhere along the line of medical school the spark becomes very $\operatorname{dim} . . . . "$ 